\title{
Pengembangan Kewirausahaan Di Universitas Mulawarman Untuk Mencetak Wirausaha Muda Yang Inovatif
}

\author{
Jawatir Pardosi ${ }^{1}$, Rudy Agung Nugroho², Julinda Manullang³, Andi Noor Asikin ${ }^{4}$ \\ ${ }^{1}$ Fakultas Keguruan dan Ilmu Pendidikan \\ ${ }^{2}$ Fakultas Matematika dan Ilmu Pengetahuan Alam \\ ${ }^{3}$ Fakultas Pertanian \\ ${ }^{4}$ Fakultas Perikanan dan Kelautan \\ Universitas Mulawarman \\ email: Pardo_si@yahoo.com
}

\begin{abstract}
The percentage of entrepreneurs is very small, it needs concrete efforts to grow and develop the entrepreneurial spirit in higher education which is expected to encourage students to be enthusiastic about entrepreneurship. The purpose of the Entrepreneurship Development Program (PPK) activity is to develop entrepreneurship at Mulawarman Universit. Socialization to students and until the end of the registration as many as 49 students / alumni registered. Implementation of entrepreneurship training activities via offline and online, training materials covering theory and practice as well as conducting field visits to advanced MSME entrepreneurs. Business proposal presentations were also conducted to determine the tenants who passed the selection. Business apprenticeship at an apprenticeship place that is in accordance with tenant business products, guidance and consultation are carried out periodically as well as assistance in the preparation of business proposals to be marketed through social media and E Commerce. The KDP website was created contained information on KDP activities and tenant products. Periodic guidance and consultation are also carried out through off line and on line as well as assistance in the preparation of scientific-based business proposals and product improvements to be marketed through social media and E Commerce.
\end{abstract}

Keywords: Entrepreneurship, Training, PPK, Mulawarman University, Tenan

\begin{abstract}
Abstrak
Persentase wirausaha sampai saat ini masih sangat kecil sehingga sangat diperlukan upaya yang kongkrit untuk menumbuhkan dan mengembangkan semangat berwirausaha di perguruan tinggi yang nantinya diharapkan agar mahasiswa semangat untuk berwirausaha. Tujuan dari kegiatan Program Pengembangan Kewirausahaan (PPK) ini adalah untuk mengembangkan kewirausahaan di Universitas Mulawarman yang berorientasi dari keilmuan dan potensi lokal sehingga menghasilkan wirausaha yang handal, mandiri dan professional. Sosialisasi ke fakultas juga Jurusan/program Studi dan sampai akhir pendaftaran sebanyak 49 orang mahasiswa/alumni mendaftar dari berbagai fakultas di Unmul. Implementasi kegiatan pelatihan kewirausahaan melalui offline dan online, materi pelatihan meliputi teori dan praktek serta melakukan kunjungan lapang ke wirausaha UMKM yang sudah maju. Dilakukan juga presentasi proposal bisnis untuk menentukan tenant yang lolos seleksi. magang usaha ditempat magang yang sesuai dengan produk usaha tenant, pembimbingan dan konsultasi serta pendampingan dalam penyusunan proposal bisnis yang berbasis pada keilmuannya dan penyempurnaan produk untuk dipasarkan melalui media social dan E Commerce
\end{abstract}

Kata Kunci: Kewirausahaan, Pelatihan, PPK, Universitas Mulawarman, Tenant

\section{PENDAHULUAN}

Dalam pembangunan ekonomi di Indonesia, kewirausahaan mempunyai peran yang sangat penting, dengan berwirausaha mampu menemukan inovasi dan gagasan baru dalam mengelola sumber 
daya alam yang tersedia (al, 1996).

Kewirausahaan merupakan proses pengembangan dan penerapan kreatifitas serta invovasi dalam menyelesaikan masalah dan mampu melihat peluang untuk menciptakan suatu usaha (Zimmerer, Thomas \& Norman, Scarborough, 2008).

Khususnya bagi para mahasiswa disamping belajar mereka juga dapat membuka usaha secara online karena dapat dilakukan di mana saja dan kapan saja. Dengan mahasiswa berwirausaha mereka mungkin akan mendapatkan penghasilan sendiri yang dimana itu bisa digunakan untuk memenuhi kebutuhan sendiri, menciptkan lapangan kerja baru apabila usaha yang mereka buat berkembang dan maju, serta dapat meningkatkan keterampilan mahasiswa itu sendiri. Karena gelar sarjana tidak akan menjanjikan seorang mahasiswa untuk mendapatkan pekerjaaan di kemudian hari. Kita liat saja, berdasarkan data Badan Pusat Statistik (BPS), per Agustus 2019, jumlah pengangguran lulusan universitas mencapai 5,67 persen dari total angkatan kerja sekitar 13 juta orang. Meski persentasenya turun dibandingkan Agustus 2018 yang 5,89 persen, angkanya di atas rata-rata pengangguran nasional yang sebesar 5,28 persen (Petrajaya, 2019).

Berdasarkan data Badan Pusat Statistik (BPS) peningkatan pertumbuhan angkatan kerja Indonesia memiliki rata-rata pertahun $1.5-2 \%$ (Hamdani, 2018). Khususnya pada Universitas Mulawarman persentase alumni yang berwirausaha hanya $0.57 \%$. Penyebabnya adalah kurangnya pengetahuan untuk menyusun proposal yang baik berbasis kewirausahaan dan minimnya kreativitas dan inovasi dan keterbaharuan yang berbasis pada bidang keilmuan (program studi). Kenyataan diatas tentu menjadi tantangan bagi Universitas Mulawarman dalam melahirkan wirausaha muda dari kampus untuk mensukseskan program Pemerintah. Berdasarkan hasil tracer study yang dilakukan sebenarnya alumni sangat berminat untuk menjadi wirausaha hanya terkendala pada kurangnya skill dan wawasan untuk bisa sukses menjadi wirausaha, motivasi yang rendah pada alumni serta sulitnya mendapatkan bantuan pendanaan untuk mengembangkan wirausaha secara mandiri.

\section{METODE PENGABDIAN \\ Pelaksanaan pelatihan Kewirausahaan secara offline dan online}

Kewirausahaan merupakan jiwa dari seseorang yang diekspresikan melalui sikap dan perilaku yang kreatif dan inovatif untuk melakukan suatu kegiatan. Kewirausahaan bukan merupakan ilmu ajaib yang mendatangkan keuntungan dalam waktu sekejap, Tapi sebuah ilmu, seni, keterampilan untuk mengelola semua keterbatasan sumber daya, informasi, dan dana yang dipakai untuk mempertahankan hidup (Maskan, 2008).

Adanya materi pelatihan dengan tujuan untuk menumbuhkan dan semangat berwirausaha sehingga memiliki mental yang siap untuk berwirausaha, serta peningkatan kreativitas untuk menghasilkan produk yang berbasis ilmu pengetahiuan/kemampuan akademik nya untuk menjadi produk yang memiliki nilai ekonomis/komersial serta keterbaharuan dalam produk. Mensiasati kondisi pandemic covid19 pelatihan dilakukan secara online dan offline dengan mengikuti protokol kesehatan dan peraturan yang berlaku di Universitas Mulawarman.

Materi pelatihan meliputi :

1. Motivasi Bisnis

2. Wirausaha berbasis perguruan tinggi

3. UltimateVision (purpose of life)

4. The spirit of leadership

5. Market segmentation

6. Business model canvas(business plan)

7. Financial literacy for begineer

8. Build a brand identity

9. Photo \& video product

10. Copy product \& storytelling 
11. Digital marketing

12. Business proposal for investor

13. Tips penyusunan proposal CPPBT dan PPBT Ristek Brin

14. Presentasi proposal bisnis tenan

\section{Sosialisasi melalui Webinar}

Sosialisasi kegiatan PPK pada tahun 2020 diawali dengan kegiatan Webinar pada bulan Juli dengan menghadirkan narasumber dari Bank Indonesia prov. Kalimantan Timur yaitu Prabu Dewanto dan juga menghadir kan narasumber Prof Esti handayani Hardi ( owner Bioperkasa ), Dr Swandari paramita yang menjelaskan protocol Covid 19 di Era Kenormalan baru juga dua orang mahasiswa Unmul yang merupakan peserta PPK pada tahun 2019 yang menyampaikan sukses sotry sebagai wirausaha. Kegiatan webinar ini juga menjadi salah satu metode untuk memberi kesempatan kepada para mahasiswa/alumni Unmul untuk mendaftar sebagai peserta program OOK.

\section{Rekruitmen Tenan}

Pendaftaran calon tenant dilaksanakan pada bulan Juli dengan mengisi form pendaftaran secara online yang sudah disiapkan oleh tim PPK Pada akhir pendaftaran maka terdapat 49 orang mahasiswa/alumni yang telah mendaftar dari berbagai fakultas dengan berbagai bidang usaha. Form pendaftaran (terlampir)

\section{Seleksi wawancara online via video call} Whatsapp

Setelah dilakukan pendaftaran diterima tenant dengan jumlah 20 orang yang terdiri dari Fkip 5 orang, FK 3 orang, FTeknik 3 orang, Faperta 6 orang, Fahut 2 orang, Fisipol 1 orang yang terdiri dari mahasiswa dan alumni Universitas Mulawarman.

\section{Calon tenant yang lolos}

Proses penetapan calon tenant dilakukan setelah melakukan seleksi wawancara online via video call WhatsApp yang dilakukan oleh tim PPK. Berdasarkan test tersebut terseleksi 20 orang mahasiswa yang akan mengikuti kegiatan PPK selanjutnya. Untuk mengikuti program PPK dengan criteria pernah merintis usaha baru dan usaha yang sedang dijalankan .

\section{HASIL DAN PEMBAHASAN}

Melalui kegiatan PPK ini akan menghasilkan wirausaha muda dari mahasiswa/alumni Unmul menjadi tenat yang kreatif dan inovatif. Output yang sudah terealisasi sampai dengan bulan agustus yaitu :

1. Publikasi koran Kaltim Post pada tanggal 15 Agustus 2020 .

2. Live streaming webinar

\section{Dampak ekonomi dan sosial}

Dampak ekonomi dan sosial yang terjadi terlihat pada tabel dibawah ini

Tabel 1 Dampak ekonomi dan sosial kegiatan PPK

\begin{tabular}{|c|c|c|c|}
\hline $\begin{array}{l}\mathbf{N} \\
\mathbf{0}\end{array}$ & $\begin{array}{c}\text { Kegiata } \\
n\end{array}$ & $\begin{array}{l}\text { Sebelum } \\
\text { kegiatan } \\
\text { PPK }\end{array}$ & $\begin{array}{c}\text { Setelah } \\
\text { kegiatan } \\
\text { PPK } \\
\text { ( Sampai } \\
\text { Dengan } \\
\text { Bulan } \\
\text { Agustus ) }\end{array}$ \\
\hline 1. & Tenant & $\begin{array}{l}\text { Rencana } \\
\text { bisnis masih } \\
\text { sederhana } \\
\text { (Jangka } \\
\text { Pendek) }\end{array}$ & $\begin{array}{l}\text { Rencana } \\
\text { bisnis mulai } \\
\text { tersusun rapi } \\
\text { dengan } \\
\text { pembuatan } \\
\text { segmentasi } \\
\text { dan BMC } \\
\text { yang di } \\
\text { lakukan } \\
\text { dalam } \\
\text { pelatihan }\end{array}$ \\
\hline 2. & Promosi & $\begin{array}{l}\text { Promosi } \\
\text { masih } \\
\text { sederhana }\end{array}$ & $\begin{array}{l}\text { Promosi yang } \\
\text { dibuat mulai } \\
\text { menjadi lebih } \\
\text { efektif dan } \\
\text { lebih pas } \\
\text { dengan target } \\
\text { pasar yang } \\
\text { dituju yang } \\
\text { diajarkan } \\
\text { selama } \\
\text { pelatihan }\end{array}$ \\
\hline 3. & Produk & $\begin{array}{l}\text { Produk } \\
\text { masih } \\
\text { sederhana } \\
\text { dan ada yang } \\
\text { belum } \\
\text { memiliki } \\
\text { produk tapi }\end{array}$ & $\begin{array}{l}\text { Sudah mulai } \\
\text { memikirkan } \\
\text { untuk } \\
\text { membuat } \\
\text { inovasi } \\
\text { produk dan } \\
\text { sudah mulai }\end{array}$ \\
\hline
\end{tabular}




\begin{tabular}{|c|c|c|c|}
\hline $\begin{array}{l}\mathbf{N} \\
\mathbf{0}\end{array}$ & $\begin{array}{c}\text { Kegiata } \\
\text { n }\end{array}$ & $\begin{array}{l}\text { Sebelum } \\
\text { kegiatan } \\
\text { PPK }\end{array}$ & $\begin{array}{c}\text { Setelah } \\
\text { kegiatan } \\
\text { PPK } \\
\text { ( Sampai } \\
\text { Dengan } \\
\text { Bulan } \\
\text { Agustus ) }\end{array}$ \\
\hline & & $\begin{array}{l}\text { sudah } \\
\text { merintis }\end{array}$ & $\begin{array}{l}\text { membentuk } \\
\text { produk yang } \\
\text { belum } \\
\text { dijalankan } \\
\text { dengan ajaran } \\
\text { yang } \\
\text { dilakukan } \\
\text { selama } \\
\text { pelatihan }\end{array}$ \\
\hline 4. & $\begin{array}{l}\text { Kualitas } \\
\text { Produk }\end{array}$ & $\begin{array}{l}\text { Kualitas } \\
\text { produk } \\
\text { belum ada di } \\
\text { uji lab }\end{array}$ & $\begin{array}{l}\text { Produk sudah } \\
\text { memasuki } \\
\text { laboratorium } \\
\text { untuk di } \\
\text { analisa nutrisi } \\
\text { yang } \\
\text { terkandung di } \\
\text { dalamnya }\end{array}$ \\
\hline 5. & $\begin{array}{c}\text { Desain } \\
\text { Kemasan } \\
\text { Produk }\end{array}$ & $\begin{array}{l}\text { Desain } \\
\text { Kemasan } \\
\text { masih } \\
\text { terbentuk } \\
\text { sederhana } \\
\text { dan seadanya }\end{array}$ & $\begin{array}{l}\text { Desain } \\
\text { Kemasan } \\
\text { mulai dibuat } \\
\text { dan diajarkan } \\
\text { menjadi lebih } \\
\text { menarik yang } \\
\text { diajarkan } \\
\text { selama } \\
\text { pelatihan }\end{array}$ \\
\hline 6. & Pasar & $\begin{array}{l}\text { Penjualan } \\
\text { masih } \\
\text { sekitaran } \\
\text { orang } \\
\text { terdekat dan } \\
\text { belum luas }\end{array}$ & $\begin{array}{l}\text { Diajarkan } \\
\text { cara untuk } \\
\text { memperluas } \\
\text { penjualan } \\
\text { dengan } \\
\text { system online } \\
\text { dan juga } \\
\text { offline dalam } \\
\text { pelatihan } \\
\text { digital } \\
\text { marketing }\end{array}$ \\
\hline 7. & $\begin{array}{l}\text { Penyusu } \\
\text { nan } \\
\text { Proposal } \\
\text { bisnis }\end{array}$ & $\begin{array}{l}\text { Belum mahir } \\
\text { dalam } \\
\text { membuat } \\
\text { proposal } \\
\text { bisnis }\end{array}$ & $\begin{array}{l}\text { Diajarkan } \\
\text { cara membuat } \\
\text { proposal } \\
\text { bisnis }\end{array}$ \\
\hline 8. & $\begin{array}{c}\text { Penyusu } \\
\text { nan } \\
\text { laporan } \\
\text { keuangan }\end{array}$ & $\begin{array}{l}\text { Penyusunan } \\
\text { laporan } \\
\text { keuangan } \\
\text { masih dalam } \\
\text { bentuk } \\
\text { sederhana } \\
\text { dan kurang } \\
\text { rapi dalam } \\
\text { administrasi } \\
\text { keuangan }\end{array}$ & $\begin{array}{l}\text { Diajarkan } \\
\text { materi } \\
\text { financial } \\
\text { literasi untuk } \\
\text { mengatur } \\
\text { laporan } \\
\text { keuangan } \\
\text { menjadi lebih } \\
\text { rapi serta } \\
\text { penyusunan }\end{array}$ \\
\hline
\end{tabular}

\begin{tabular}{|l|c|c|c|}
\hline $\mathbf{N}$ & Kegiata & $\begin{array}{c}\text { Sebelum } \\
\text { kegiatan } \\
\text { PPK }\end{array}$ & $\begin{array}{c}\text { Setelah } \\
\text { kegiatan } \\
\text { PPK } \\
\end{array}$ \\
& & & ( Sampai \\
& & & $\begin{array}{c}\text { Dengan } \\
\text { Bulan } \\
\text { Agustus ) }\end{array}$ \\
\hline & & & HPP yang \\
& & & baik \\
\hline
\end{tabular}

\section{Kontribusi Mitra Terhadap pelaksanaan}

Kegiatan PPK ini bermitra dengan Bank Indonesia yang turut berkontribusi dalam pelaksanaan kegiatan webinar serta dalam kunjungan studi lapang UMKM yang sudah maju sebagai sarana pembelajaran tenant PPK di lapang.

\section{SIMPULAN}

Kegiatan PPK berjalan dengan baik dengan diikuti 20 orang calon tenant dari berbagai fakultas dari Fakultas Teknik, Fakultas Pertanian, Fakultas Kedokteran, Fakultas Ilmu keguruan dan Pendidikan, Fakultas Ilmu sosial dan Politik. Kegiatan PPK telah berjalan dengan baik yang menciptakan usaha tenant menjadi ciri khas di Kalimantan Timur.

\section{UCAPAN TERIMAKASIH}

Terimakasih diucapkan kepada Direktorat Riset dan Pengabdian Masyarakat Kementrian Riset, Teknologi, dan Pendidikan Tinggi Badan Riset dan Inovasi Nasional, atas hibah Pengabdian Kepada Masyarakat Tahun Anggaran 2020.

\section{DAFTAR PUSTAKA}

\section{[1] al, Z. W. (1996). Entrepreneurship} and The New Venture Formation. New Jersey: Prentice hall.

[2] Hamdani. (2018, Agustus 19). Kompasiana. Retrieved from Kompasiana.com: https://www.kompasiana.com/cangk 
oiburong/5b78e7e743322f032835da

b4/minat-mahasiswa-berwirausahamengalami-

peningkatan?page=all\#sectionall

[3] Maskan, M. (2008). Kewirausahaan. Polinema Press.

[4] Petrajaya. (2019, Agustus 21). Pentingnya Berwirausaha bagi mahasiswa. Retrieved from Campuspedia: https://campuspedia.id/kabar/pentin gnya-berwirausaha-bagimahasiswa-di-masa-perkuliahan/

[5] Zimmerer, Thomas \& Norman, Scarborough. (2008).

Kewirausahaan dan Manajemen Usaha Kecil. Jakarta: Salemba Empat. 